\title{
PARTICIPAÇÃO DAS PEQUENAS EMPRESAS DA REGIÃO NORTE NOS PROGRAMAS DE FINANCIAMENTO DA FINEP NOS ANOS DE 2006 A 2016
}

Ricardo Ferreira Bruno ${ }^{1}$

Marcela Barbosa De Moraes ${ }^{1}$

Edson Aparecida De Araujo Querido Oliveira ${ }^{1}$

\footnotetext{
${ }^{1}$ Programa Pós-Graduação em Gestão e Desenvolvimento Regional / Departamento de Gestão e Negócios / Universidade de Taubaté (UNITAU)
} 


\title{
PARTICIPAÇÃO DAS PEQUENAS EMPRESAS DA REGIÃO NORTE NOS PROGRAMAS DE FINANCIAMENTO DA FINEP NOS ANOS DE 2006 A 2016
}

\begin{abstract}
Resumo: Vários estudos enfatizam que as pequenas empresas têm contribuído economicamente para o desenvolvimento do país. Nos últimos anos, o Governo Federal tem aumentado gradativamente os incentivos ao desenvolvimento da inovação nessas empresas. Neste quesito, destaca-se a Financiadora de Estudos e Projetos (FINEP) que possui linhas de financiamento específicas ao incentivo da inovação para as pequenas empresas, com o objetivo de aumentar o conhecimento científico e tecnológico do país. Neste contexto, o objetivo deste artigo é verificar a participação das pequenas empresas, localizadas na região Norte, nas linhas de financiamento da FINEP no período de 2006 a 2016. Para tanto, a metodologia utilizada foi uma abordagem qualitativa e descritiva. $\mathrm{O}$ procedimento de coleta de dados foi documental dos relatórios fornecidos pela FINEP. Após a análise, verificou-se um número pequeno de projetos contratados pelas empresas analisadas, totalizando sete projetos e conclui-se que as pequenas empresas localizadas na Região Norte têm pouco acesso aos programas de fomento à inovação promovido pelo Governo Federal.
\end{abstract}

Palavras-chave: Inovação. Pequena Empresa. Fomento Público. FINEP. 


\section{Introdução}

Diante do cenário de instabilidade econômica que o país está passando, as empresas de pequeno porte são vistas como um importante impulsionador do desenvolvimento regional. Acs, Carlsson e Karlsson (1999) evidenciam que, nas crises do petróleo dos anos de 1970, as empresas de pequeno porte foram de grande importância, especialmente nas situações de saída da crise e retomada do desenvolvimento, por gerarem empregos líquidos mais rapidamente dos que as empresas de grande porte.

Em paralelo, Mendes e Kanikadan (2016) argumentam que para as empresas obtenham sucesso e consigam sobreviver no mercado precisa: inovar em produtos e serviços, pensar de forma estratégica e organizada a gestão do negócio e devem estar sempre atentas as mudanças decorrentes dos ambientes tanto interno quanto externo a organização. Os autores reforçam que a capacidade de inovação das empresas está ligada às novas tendências de mercado e avanços tecnológico, bem como a forma como a empresa se organiza.

Como mencionado e frente a capacidade de geração de emprego e renda apresentada pelas pequenas empresas e sua forma de disseminar novas tecnologias devido a sua distribuição geograficamente desconcentrada (KOTESKI, 2004), as atenções têm se voltado para estas empresas, devido a significativa contribuição ao desenvolvimento da economia brasileira (TERENCE, 2002).

Para que tais contribuições se tornem cada vez mais relevantes faz-se necessário que as pequenas empresas sejam incluídas nas linhas de crédito de incentivos à inovação. Porém, Moreira (2010) destaca que obter fomento para inovação é um dos maiores desafios enfrentados por estas empresas.

Para minimizar essa dificuldade, as políticas públicas de incentivo à inovação são fundamentais para as pequenas empresas, principalmente as de base tecnológica, tenham acesso às linhas de crédito subsidiadas e com prazos de pagamentos diferenciados, potencializando a criação de novas tecnologias.

No Brasil, o Governo Federal, por meio da Financiadora de Estudos e Projetos (FINEP), promove políticas públicas de fomento à inovação para empresas de pequeno porte. Essa instituição tem como missão promover o desenvolvimento econômico social do Brasil por meio do fomento público à ciência, tecnologia e inovação em empresas, universidades, institutos tecnológicos e outras instituições públicas ou privadas (SILVA et al., 2015).

Com base no cenário descrito e considerando a importância de incentivar a inovação nas pequenas empresas, está pesquisa buscou verificar a participação das pequenas empresas localizadas na região Norte do País, nas linhas de financiamento da FINEP, no período de 2006 a 2016.

\section{Referencial Teórico}

\subsection{Inovação em Pequenas Empresas}


As pequenas empresas no Brasil encontram-se inseridas em um ambiente altamente competitivo no qual a busca pela eficiência e a maximização da produtividade são fatores primordiais à permanência e/ou sobrevivência para estas empresas.

Conforme Moraes, Lima e Lobosco (2011) as estratégias de inovação têm se tornado fundamentais para que a maioria das empresas tenha sua sobrevivência garantida, pois é por meio da inovação que as condições de competir com a concorrência são proporcionadas, além de suprir a necessidade de demanda do mercado.

De acordo com Schumpeter (1982), a inovação é tratada como o elemento motriz da evolução do capitalismo, seja a inovação em forma de introdução de novos bens ou técnicas de produção, ou mesmo pelo surgimento de novos mercados, fontes de oferta de matérias primas ou composições industriais. Para Pereira et al. (2009), as causas para o sucesso das organizações estão intimamente ligadas à capacidade dessas empresas inovarem no processo de gestão e no uso de novas tecnologias.

Para Schumpeter (1982, p.48-49), as inovações "são representadas pela combinação de materiais e forças disponíveis no mercado, porém, estas combinações devem ocorrer de forma diferente da existente no mercado, pois a realização de novas combinações dá origem ao processo de desenvolvimento econômico". Este conceito pode ser estendido a cinco casos citados pelo autor: 1) introdução de um novo bem ou nova qualidade de bem; 2) novo método de produção; 3 ) abertura de um novo mercado; 4) nova fonte de oferta de matéria-prima; e 5) estabelecer uma nova forma de organização da indústria.

Em acordo com esse conceito, Gonçalves e Gomes (1993), acrescentam ao ato de inovar, o fato de gerar mudança e ou alteração nos processos de produção e nos modelos de produtos, o que contribui para o avanço tecnológico e o desenvolvimento das organizações.

Conforme Feitosa e Teixeira (2015), as empresas de todos os tamanhos procuram inovar com o objetivo de serem mais competitivas e, para tal, produzem alta tecnologia em bens e serviços, criam fluxos econômicos e dinamismo como o objetivo de apoiar o desenvolvimento do trabalho.

Os principais motivos que levam as empresas a buscar inovação normalmente são decorrentes das necessidades de desenvolver e implementar novas tecnologias para tornar a produção mais eficiente e eficaz, as pressões de concorrência, bem como as mudanças nos ambientes negociais (BOTELHO, CARRIJO, KAMASAKI, 2007; FEITOSA, TEIXEIRA, 2015, LA ROVERE, 1999, OSIRO et al., 1999).

Diante deste cenário, Feitosa e Teixeira (2015) destacam que as pequenas empresas, comparadas as grandes empresas, possuem algumas características que auxiliam a inovação, tais como: (1) número reduzido de funcionários, tornando-as ágeis e flexíveis às mudanças; (2) estrutura hierárquica com poucos níveis, reduzindo a burocracia; (3) normalmente são geridas pelo proprietário tornando as tomadas de decisões um processo rápido e (4) pessoalidade com os clientes. Para os teóricos, estes fatores potencializam a atividade de inovação dentro da pequena empresa.

Contudo, deve-se destacar que as pequenas empresas também encontram desvantagens para produzir a inovação, tais como as apontadas por Maçaneiro (2008); Feitosa e Teixeira (2015); Caron (2003), a saber: a) falta de recursos financeiros; b) percepção de importância da inovação; c) pouca ou nenhuma informação sobre as entidades de apoio a inovação tecnológica; d) falta de informação sobre as mudanças tecnológicas; e) falta de pessoal capacitado.

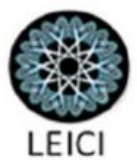


No entanto, mesmo diante destes óbices, faz-se necessário incentivar os investimentos em inovação nas pequenas empresas devido ao grande potencial de desenvolvimento local e regional que apresentam, além da grande abrangência geográfica e capacidade de geradora de emprego e renda que as tornam tão importantes economicamente. Conforme Silva, Moraes e Oliveira (2016), a inovação é propiciadora de novas oportunidades com as quais são possíveis influenciar os rumos do mercado, pois favorece a implementação de novos produtos e serviços, criando novas perspectivas para a empresa, tanto de pequeno como de médio porte.

\subsection{Fomento à Inovação por meio da Financiadora de Estudos e Projetos (FINEP)}

$\mathrm{O}$ apoio financeiro às pequenas empresas tem sido evidenciado como fator preponderante para permanência, sobrevivência e oportunidade de desenvolvimento, crescimento e geração de emprego e renda (PEREIRA et al., 2009; NUNES; MIRANDA; FERREIRA, 2011; OLIVEIRA et al., 2016).

De acordo com Moreira (2010, p. 5), "a obtenção de crédito é um dos maiores problemas da pequena produção, ao lado do excesso de burocracia e de impostos e das dificuldades de acesso à tecnologia e ao conhecimento". Corroborando com esta assertiva, Holanda, Moura, Mahl (2015) discorrem que existe um número elevado de pequenas empresas no Brasil com potencial inovador, porém estas empresas encontram grandes dificuldades de implantar e concretizar suas ideias, pois, encontram barreiras como pessoal qualificado e recursos financeiros mais escassos.

Em consonância com este cenário, Silva et al. (2015) discorrem que, além das dificuldades já citadas as pequenas empresas devem lidar com os riscos e incertezas do mercado. Os autores salientam que as incertezas são específicas dos projetos de inovação e que não existe a possibilidade de as mesmas serem eliminadas ou descontadas tendo em vista que estão presentes em todos os projetos que requerem tempo para maturação, como é o caso dos projetos de inovação.

Para Holanda, Moura, Mahl (2015, p. 38), as pequenas empresas que conseguem “investir em inovação e, portanto, possuem fomento externo para tal, tornam-se mais competitivas, e a consequência disso é percebida na própria taxa de sobrevivência das empresas". Os autores reforçam que o financiamento e a inovação estão fortemente ligados.

Diante da relevância das pequenas empresas na economia nacional, fez-se necessário que a iniciativa pública promovesse políticas de apoio e incentivo à inovação específicas para essas empresas. Conforme Holanda, Moura, Mahl (2015, p. 38), o Brasil, nas últimas décadas, tem promovido novos instrumentos de estímulo à inovação "baseado em incentivos físcais, fundos setoriais para desenvolvimento de projetos e na diversificação de distribuição dos recursos financeiros para $\mathrm{P} \& \mathrm{D}$ ”. Estes incentivos passaram a ser direcionados às empresas nacionais e deixaram de ser destinados exclusivamente às universidades.

Para que as empresas pudessem ter maior proximidade com a inovação, em 24 de julho de 1967, foi criada a FINEP (Financiadora de Estudos e Projetos), empresa pública vinculada ao Ministério do Planejamento. Já na década de 1970 teve seu escopo ampliado, passando a atuar em toda a cadeia de pré investimento, apoiando estudos e projetos, pesquisa e desenvolvimento de tecnologias, formação de recursos humanos de alto nível e sua absorção

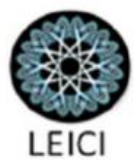


no mercado de trabalho nacional, até a aplicação das tecnologias no aparato produtivo (SILVA et al., 2015).

Na década de 1980, o Decreto-Lei No 2.275/1985 cria o Ministério da Ciência e Tecnologia, ao qual a Finep passa a ficar vinculada. Na década de 2000, a FINEP passa por algumas transformações, tais como criação de diversos fundos setoriais nos anos de 2000, 2001 e 2004. No ano de 2005 é aprovada a Lei do Bem no 11.196/05, regulamentada pelo Decreto 5.798 de 07.07.2006, que trata dos incentivos à inovação tecnológica. Em 2006, a Finep passa a operar com a modalidade Subvenção Econômica (SILVA et al., 2015).

A FINEP é uma das principais agências de fomento à inovação tecnológica no país e seu perfil de atuação está descrito como: "Atuar em toda a cadeia da inovação, com foco em ações estratégicas, estruturantes e de impacto para o desenvolvimento sustentável do Brasil." Tem como missão: "Promover o desenvolvimento econômico e social do Brasil por meio do fomento público à Ciência, Tecnologia e Inovação em empresas, universidades, institutos tecnológicos e outras instituições públicas ou privadas" (SILVA et al., 2015).

O apoio da FINEP abrange todas as etapas e dimensões do ciclo e desenvolvimento científico e tecnológico que correspondem à pesquisa básica e aplicada, melhoria de produtos, serviços e processos. Opera com três grandes linhas: apoio a inovação em empresas, apoio às Instituições Científicas e Tecnológicas (ICTs).

Os apoios proporcionados podem ser não reembolsáveis destinados às Instituições Científicas e Tecnológicas (ICTs) estes recursos são originários de Fundos Setoriais e reembolsáveis concedidos à instituições que demonstrem capacidade de pagamento e condições para desenvolver projetos.

Com relação ao apoio financeiro às empresas, a FINEP possui diversas modalidades de crédito com encargos reduzidos e prazos adequados abrangendo diversas áreas de negócios, todas com o objetivo de fomentar a inovação no país.

Conforme De Negri e Morais (2016, p. 20) "grandes volumes de recursos que foram alocados para a Finep, que atua como Secretaria Executiva dos Fundos Setoriais", têm grande abrangência e diversos programas que ampliaram o envolvimento e criando novas ações que objetivaram alcançar com mais intensidade as instituições de ciência e tecnologia nos estados, o que fez com que a FINEP se torne como um órgão imprescindível e basilar no apoio à inovação.

Dentre as diversas linhas, destaca-se algumas direcionadas às pequenas empresas, com juros reduzidos e diferenciais para estas empresas, conforme Tabela 1 abaixo.

Tabela 1: Modalidade de Apoio Financeiro às Pequenas Empresa

\begin{tabular}{|c|c|c|c|c|}
\hline Programas & $\begin{array}{l}\text { Modalidade de apoio } \\
\text { financeiro }\end{array}$ & Condições & Condições & Condições \\
\hline \multirow{2}{*}{$\begin{array}{l}\text { Juro Zero } \\
\quad(2006)\end{array}$} & \multirow{2}{*}{$\begin{array}{l}\text { Investimentos para } \\
\text { inovação: micro e } \\
\text { pequenas empresas }\end{array}$} & $\begin{array}{c}\text { Faturamento: }<\mathrm{R} \$ \\
10,5 \text { milhões }\end{array}$ & \multirow{2}{*}{$\begin{array}{c}\text { ICTs nos estados para } \\
\text { pré-qualificação das } \\
\text { empresas }\end{array}$} & \multirow{2}{*}{$\begin{array}{l}\text { Zero, mas } \\
\text { com } \\
\text { correção do } \\
\text { IPCA sem o } \\
\text { capital }\end{array}$} \\
\hline & & Prazo: 100 meses & & \\
\hline & & & & \\
\hline
\end{tabular}




\begin{tabular}{|c|c|c|c|c|}
\hline $\begin{array}{c}\text { Subvenção } \\
\text { a empresas } \\
(\mathbf{2 0 0 6 )}\end{array}$ & $\begin{array}{c}\text { Subvenção para custeio } \\
\text { de inovações }\end{array}$ & $\begin{array}{c}\text { Grandes empresas; } \\
\text { MPEs Contratação de } \\
\text { pesquisadores }\end{array}$ & $\begin{array}{c}\text { Setores PITCE para } \\
\text { MPEs }\end{array}$ & $\begin{array}{c}\text { Recursos a } \\
\text { fundo } \\
\text { perdido }\end{array}$ \\
\hline $\begin{array}{c}\text { Pappe } \\
\text { Subvenção } \\
(\mathbf{2 0 0 6 )}\end{array}$ & $\begin{array}{c}\text { Subvenção para custeio } \\
\text { de inovações de MPEs, } \\
\text { via instituições } \\
\text { estaduais e locais }\end{array}$ & $\begin{array}{c}\text { Seleção de } \\
\text { instituições regionais, } \\
\text { estaduais ou locais }\end{array}$ & $\begin{array}{c}\text { Setores PITCE e PDP2 } \\
\text { Valódito: R\$ do } \\
50 \text { mil a R } \$ \\
500 \text { mil }\end{array}$ \\
\hline
\end{tabular}

Fonte: De Negri e Morais (2016)

\section{Método de Pesquisa}

Para Marconi e Lakatos (1990), a metodologia é a explicação minuciosa, rigorosa e exata de toda ação desenvolvida no método (caminho) do trabalho de pesquisa. Deste modo, esta pesquisa é classificada como descritiva, que, de acordo com Gressler (2004), descreve, sistematicamente, fatos e características presentes em uma determinada população ou área de interesse. Seu interesse principal está voltado para o presente e consiste em descobrir "o que é?".

Por possuir tais característica, o método de estudo foi selecionado a fim de descrever a participação das pequenas empresas da região Norte e os projetos que foram contratados pela FINEP nos anos de 2006 a 2016. Diante disto, os dados foram coletados por meio de documentos provenientes do website da FINEP referentes aos incentivos governamentais cedidos no período de análise.

O universo de pesquisa foi composto pelos projetos contratados no período de 2006 a 2016 na região norte do país, composta pelos estados do Acre, Amapá, Amazonas, Pará, Rondônia, Roraima e Tocantins, totalizando 312 projetos, deste total 278 foram projetos não reembolsáveis, ou seja, destinados à Instituições Científicas e Tecnológicas (ICTs) e somente 34 projetos foram comtemplados nas categorias subvenção e reembolsáveis, os quais podem ser destinados às empresas privadas.

Os dados foram analisados por meio de templates e que contém as informações referentes aos valores dos projetos, porte da empresa e natureza dos projetos contratados. As análises foram feitas projeto a projeto para identificação de quais foram obtidos por pequenas empresas no período aferido.

\section{Análise dos Projetos contratados na Região Norte nos anos de 2006 a 2016}

Os projetos contratados e aprovados pela direção da FINEP são implementados por instrumento de execução formal. A Tabela 2 demonstra os projetos contratados na Região Norte de nosso país, nas modalidades: não reembolsáveis, reembolsáveis e subvenção. Também destaca os projetos destinados às micro e pequenas empresas desta mesma região. $\mathrm{O}$ período de pesquisa compreende os anos de 2006 a 2016. 
Tabela 2: Projetos Contratados nos anos de 2006 a 2016 na Região Norte do País

\begin{tabular}{|c|c|c|c|c|c|c|c|c|c|c|c|c|}
\hline Região Norte & $\mathbf{2 0 0 6}$ & $\mathbf{2 0 0 7}$ & $\mathbf{2 0 0 8}$ & $\mathbf{2 0 0 9}$ & $\mathbf{2 0 1 0}$ & $\mathbf{2 0 1 1}$ & $\mathbf{2 0 1 2}$ & $\mathbf{2 0 1 3}$ & $\mathbf{2 0 1 4}$ & $\mathbf{2 0 1 5}$ & $\mathbf{2 0 1 6}$ & Total \\
\hline $\begin{array}{c}\mathbf{N}^{\mathbf{0}} \text { de Projetos } \\
\text { Contratados }\end{array}$ & 84 & 45 & 38 & 28 & 42 & 16 & 22 & 25 & 8 & 2 & 2 & $\mathbf{3 1 2}$ \\
\hline $\begin{array}{c}\mathbf{N}^{\mathbf{0}} \text { de Projetos } \\
\text { Contratados } \\
\text { por Pequenas } \\
\text { Empresas }\end{array}$ & 0 & 0 & 2 & 2 & 1 & 1 & 1 & 0 & 0 & 0 & 0 & $\mathbf{7}$ \\
\hline
\end{tabular}

Fonte: FINEP (2017)

Como demonstrado na Tabela 2, tem-se um número muito inexpressivo de adesão às linhas de financiamentos destinados à pequenas empresas. Esta falta de adesão sucita alguns questionamentos tendo em vista que este seguimento de empresas segundo dados disponibilizados pelo Sebrae (2014) são um número expressivo de empresas, ou seja, as micro e pequenas empresas representaram, em 2011, nas atividades de serviços e de comércio, respectivamente, $98 \%$ e $99 \%$ do total de empresas formalizadas.

A expressividade das micro e pequenas empresas não estão expressas em sua participação no acesso às linhas de crédito para incentivo à inovação e isto pode ser em decorrência dos principais entraves e dificuldades vivenciados por estas empresas que, segundo Ribeiro, Moraes e Ruiz (2010) são: má elaboração de projetos, atraso nas licitações, entraves burocráticos, dificuldades para elaboração de relatório técnico, dificuldades na quantificação dos dados e dificuldade na interação entre instituições.

De acordo com o Manual de Programa Subvenção Econômica à Inovação Nacional, os processos de chamadas públicas têm os seguintes prazos:

- Habilitação, prazo estimado de cerca de 30 dias;

- Análise, com duração estimada de 60 dias;

- Análise conclusiva, prazo estimado de 75 dias;

- Homologação, com duração de aproximadamente 30 dias.

O período inteiro desde o início do processo até a homologação, tem prazo total de aproximadamente 195 dias, isto sem a garantia que o projeto será aprovado. Se após todas estas etapas, o projeto for aprovado, seguem-se as etapas de liberação do valor do projeto.

Conforme demonstrado por Moreira (2010), Holanda, Moura e Mahl (2015), além das dificuldades financeiras, a falta de pessoal qualificado e a burocracia são fatores inibidores para que as pequenas empresas possam inovar e, consequentemente, obter as linhas de crédito para este tipo de incentivo. O período entre a habilitação da empresa e a liberação do recurso é considerado longo para a maioria das pequenas empresas, o que se torna um fator de relevante dificuldade, principalmente no que diz respeito às habilidades de se programar e lidar com as burocracias existentes.

A Tabela 3 detalha os projetos contratados na região Norte do país no período de 2006 a 2009. É importante evidenciar que os anos 2006 e 2007, não tiveram projetos aprovados pela

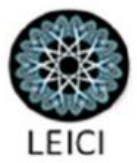


FINEP. Quanto à sua natureza, somente 4 projetos foram contratados por Pequena Empresa, isto de um total de 195 projetos.

Tabela 3 - Projetos contratados nos anos de 2006 a 2009.

\begin{tabular}{|c|c|c|c|c|}
\hline Contratos & 01.08.0109.00 & 01.08 .0102 .00 & 01.09 .0481 .00 & 01.09 .0264 .01 \\
\hline Ano & 2008 & 2008 & 2009 & 2009 \\
\hline Estado & $\mathrm{AM}$ & PA & RO & AM \\
\hline $\begin{array}{c}\text { Segmento da } \\
\text { empresa }\end{array}$ & $\begin{array}{l}\text { Fabricação de frutas } \\
\text { cristalizadas, balas e } \\
\text { semelhantes }\end{array}$ & $\begin{array}{c}\text { Suporte técnico, } \\
\text { manutenção e outros } \\
\text { serviços em tecnologia } \\
\text { da informação }\end{array}$ & $\begin{array}{l}\text { Fabricação de } \\
\text { ferramentas }\end{array}$ & $\begin{array}{l}\text { Fabricação de } \\
\text { produtos farmo- } \\
\text { químicos }\end{array}$ \\
\hline $\begin{array}{l}\text { Título do } \\
\text { Contrato de } \\
\text { Subvenção }\end{array}$ & $\begin{array}{l}\text { Adequação de } \\
\text { produtos com frutas } \\
\text { regionais para } \\
\text { exportação }\end{array}$ & $\begin{array}{l}\text { Suporte ao Planejamento } \\
\text { Estratégico de } \\
\text { Segurança Pública da } \\
\text { PM-PA com técnicas de } \\
\text { Mineração e } \\
\text { Visualização de } \\
\text { Informações em Mapas } \\
\text { Digitais Dinâmicos }\end{array}$ & $\begin{array}{l}\text { Transmissão variadora } \\
\text { de velocidade, que } \\
\text { contempla o } \\
\text { movimento zero e a } \\
\text { inversão de sentido de } \\
\text { giro, sem desengreno. }\end{array}$ & $\begin{array}{l}\text { Desenvolvimento de } \\
\text { Óleo de Copaíba em } \\
\text { Cápsulas Mole }\end{array}$ \\
\hline Modalidade & Não reembolsável & Não reembolsável & Não reembolsável & Não reembolsável \\
\hline Demanda & $\begin{array}{l}\text { Chamada Pública } \\
\text { MCT/FINEP } \\
\text { Subvenção } \\
\text { Econômica à } \\
\text { Inovação 01/2007 }\end{array}$ & $\begin{array}{c}\text { Chamada Pública } \\
\text { MCT/FINEP Subvenção } \\
\text { Econômica à Inovação } \\
01 / 2007\end{array}$ & $\begin{array}{l}\text { Chamada Pública } \\
\text { MCT/FINEP- } \\
\text { Subvenção Econômica } \\
\text { à Inovação 01/2008 }\end{array}$ & $\begin{array}{l}\text { Chamada Pública } \\
\text { MCT/FINEP- } \\
\text { Subvenção } \\
\text { Econômica à } \\
\text { Inovação 01/2008 }\end{array}$ \\
\hline $\begin{array}{l}\text { Valor do } \\
\text { projeto }\end{array}$ & $500.040,00$ & $642.081,01$ & $1.307 .543,86$ & $1.276 .400,00$ \\
\hline $\begin{array}{c}\text { Valor } \\
\text { liberado }\end{array}$ & $500.040,00$ & $642.081,01$ & $1.307 .543,86$ & $1.276 .400,00$ \\
\hline Vigência & $15 / 04 / 08-15 / 04 / 11$ & $11 / 04 / 08-11 / 10 / 11$ & $15 / 10 / 09-15 / 10 / 13$ & $25 / 06 / 09-25 / 04 / 14$ \\
\hline
\end{tabular}

Fonte: FINEP (2017)

Os projetos liberados no referido período foram todos na modalidade subvenção econômica que tem como objetivo promover um significativo aumento das atividades de inovação e o incremento da competitividade das empresas e da economia do País. Os projetos foram enquadrados na modalidade de projeto não reembolsável. Essa modalidade de apoio financeiro consiste na aplicação de recursos públicos não reembolsáveis (que não precisam ser devolvidos) diretamente em empresas, para compartilhar com elas os custos e riscos inerentes a tais atividades. 
Os projetos foram provenientes de três estados da região (Amazonas, Pará e Rondônia), de um total de 7 Estados, o que demonstra dificuldades de empresas destes Estados em acessar as linhas de financiamento.

A Tabela 4 detalha os projetos contratados nos anos de 2010 a 2016 na região Norte do país. Quanto à sua natureza, somente 3 projetos foram contratados por Micro e Pequena Empresa de um total de 117 projetos.

Tabela 4 - Projetos contratados nos anos de 2010 a 2016.

\begin{tabular}{|c|c|c|c|}
\hline Contratos & 03.10 .0451 .00 & 03.11 .0016 .00 & 03.12 .0430 .00 \\
\hline Ano & 2010 & 2011 & 2012 \\
\hline Estado & PA & RO & $\mathrm{AM}$ \\
\hline $\begin{array}{l}\text { Segmento da } \\
\text { empresa }\end{array}$ & $\begin{array}{l}\text { Manutenção e reparação de } \\
\text { embarcações e estruturas } \\
\text { flutuantes }\end{array}$ & $\begin{array}{l}\text { Representantes comerciais } \\
\text { e agentes do comércio de } \\
\text { instrumentos e materiais } \\
\text { odonto-médico } \\
\text { hospitalares }\end{array}$ & $\begin{array}{c}\text { Fabricação de cosméticos, } \\
\text { produtos de perfumaria e } \\
\text { de higiene pessoal }\end{array}$ \\
\hline $\begin{array}{l}\text { Título do Contrato } \\
\text { de Subvenção }\end{array}$ & $\begin{array}{l}\text { Desenvolvimento de } \\
\text { componentes modulares para } \\
\text { uso na construção de } \\
\text { habitações de interesse } \\
\text { social utilizando produto } \\
\text { inovador como substituto da } \\
\text { madeira, obtido da } \\
\text { reciclagem de lama } \\
\text { vermelha }\end{array}$ & $\begin{array}{c}\text { Avaliação de efetividade } \\
\text { de substrato de absorção } \\
\text { em sistemas } \\
\text { concentradores para } \\
\text { obtenção de oxigênio } \\
\text { medicinal }\end{array}$ & $\begin{array}{l}\text { Frasco de cerâmica com } \\
\text { válvula de recrave e design } \\
\text { de origem iconográfica da } \\
\text { cultura amazônica para } \\
\text { perfume }\end{array}$ \\
\hline Modalidade & Não reembolsável & Não reembolsável & Não reembolsável \\
\hline Demanda & $\begin{array}{c}\text { SEL. PÚB. } \\
\text { MCT/FINEP/FNDCT/SUBV } \\
\text { Econômica à inovação - } \\
\text { 01/2009 - ÁREA 6: } \\
\text { Desenvolvimento Social }\end{array}$ & $\begin{array}{l}\text { Seleção pública prêmio } \\
\text { FINEP } 2009 \text { - subvenção }\end{array}$ & $\begin{array}{l}\text { Seleção pública prêmio } \\
\text { FINEP } 2011 \text { - subvenção }\end{array}$ \\
\hline Valor do projeto & $1.146 .676,00$ & $500.000,00$ & $500.000,00$ \\
\hline Valor liberado & $1.146 .676,00$ & $500.000,00$ & $265.151,00$ \\
\hline Vigência & 20/09/10 - 20/09/13 & 18/02/11 - 18/11/13 & 21/11/12 - 21/11/13 \\
\hline
\end{tabular}

Fonte: FINEP (2017)

O período de 2010 a 2016 se mostrou semelhante ao período de 2006 à 2009 no qual todos os projetos foram na modalidade de subvenção e não reembolsável e concentrados nos 
mesmos três estados da região (Amazonas, Pará e Rondônia), porém, neste período, a quantidade de projetos foi menor que no período anterior.

O que pode ser verificado no período de 2006 a 2016, (um horizonte de 10 anos) é que o número de pequenas empresas beneficiadas pelas linhas de financiamento foi pequeno (sete empresas). Isso pode ser justificado pela pouca capacidade de planejamento destas empresas e se for considerada a explicação de Pereira et al. (2009) a pequena empresa possui um sistema que via de regra não é logicamente ordenado e o desafio do planejamento consiste na passagem do terreno das ideias para a ação concreta. Salientam ainda que as atividades de planejamento, são complexas em decorrência da própria natureza de pensar o futuro e que esta é uma das atividades mais complexas que o ser humano pode se envolver.

Estas barreiras se mostram, de fato, evidentes tendo em vista que, conforme já citado, as micro e pequenas empresas não possuem pessoal capacitado para tais tarefas de planejamento e trâmites burocráticos.

Cabe destacar que no período pesquisado, além do número pequeno de empresas beneficiadas, nenhuma pequena empresa dos estados do Acre, Amapá, Roraima e Tocantins puderam se beneficiar com as linhas de crédito oferecido pela FINEP. Além disso nos anos 2006, 2007 e 2013 a 2016 nenhum projeto foi financiado para estas empresas.

\section{Considerações Finais}

A pesquisa buscou analisar os projetos contratados pela FINEP no período de 2006 a 2016, destinados às pequenas empresas da região Norte do país e para tal, expôs os projetos contratados. A FINEP se propõe a ser um agente de facilitação ao acesso à inovação, porém os dados pesquisados indicam que o acesso não se demostra tão simples no que diz respeito às micro e pequenas empresas, e ainda que o poder público possa intervir tornando o ambiente para acesso a essas linhas mais propício e menos burocrático.

A abrangência das linhas de crédito da FINEP se mostrou baixa quando foram relacionados a quantidade de projetos contratados no período e a adesão das micro e pequenas empresas, tendo em vista que de um total de 312 projetos, somente 7 foram tomados por essas empresas, o que representa aproximadamente $2,24 \%$ dos projetos contratados.

Esta pouca abrangência pode significar que as pequenas empresas não estão, de fato, conseguindo ter acesso as essas fontes de financiamento devido aos processos burocráticos que as linhas de financiamento possuem. Com isso, muitas empresas podem inclusive estar utilizando recursos próprios como fonte de investimento em inovação.

Essas linhas de crédito ainda são consideradas pelas pequenas empresas um desafio, tendo em vista que a burocracia para a liberação de recursos é muito grande. Também fica evidente que as empresas que conseguem se utilizarem destas linhas de crédito obtém impactos altamente significativos, pois os recursos as auxiliam a se diferenciarem no mercado e, por consequência, terem maior competitividade e geração de emprego e renda, proporcionando uma importante contribuição social.

Quando se observa os referenciais teóricos, resta evidente que, mesmo que as pequenas empresas tenham conhecimento dos editais e linhas de crédito existentes, o número de empresas

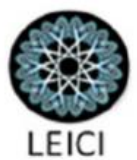


que acessam essas linhas ainda é extremamente pequeno e isso se dá devido às dificuldades de enquadramento já evidenciadas.

Faz se necessário voltar à atenção, a inclusão das pequenas empresas no desenvolvimento tecnológico e inovativo, tendo em vista sua grande abrangência territorial e contribuição com a democratização do conhecimento para que os mesmos não fiquem restritos às universidades e centro de pesquisas.

\section{Referências}

ACS, Z. J., CARLSSON, B.; KARLSSON, C. The Linkages among Entrepreneurship, SMEs and the Macroeconomy. In: ACS, Z. J., CARLSSON, B. \& KARLSSON, C. (eds.). Entrepreneurship, Small and Medium-Sized Enterprises and Macroeconomy. Cambridge: Cambridge University Press, p. 3-42, 1999.

BRASIL. Lei complementar $n^{\circ}$ 123, de 14 de dezembro de 2006. Disponível em: http://www.planalto.gov.br/ccivil_03/leis/LCP/Lcp123.htm Acesso em: 05 de agosto de 17.

BOTELHO; M. R. A.; CARRIJO; M. C.; KAMASAKI; G. Y. Inovações, Pequenas Empresas e Interações com Instituições de Ensino/Pesquisa em arranjos produtivos locais de setores de tecnologia avançada. Revista Brasileira de Inovação, v. 6 n. 2 p.331-371, 2007.

CARON, A. Inovações tecnológicas nas pequenas e médias empresas industriais em tempos de globalização. O Caso do Paraná. Curitiba, 2003. Tese de doutorado em engenharia da produção - UFSC.

DE NEGRI, J. A.; MORAIS, J. M. Evolução das ações e programas da FINEP no apoio à inovação empresarial: 2003-2014. Radar, Dez. 2016.

FEITOZA, R. A. A.; TEIXEIRA, R. M. Inovação na Pequena Empresa: Mapeamento da produção científica internacional e nacional no período de 2000 à 2014. Revista da Micro e pequena empresa, v. 9, n. 1, p. 90-102, 2015.

FINANCIADORA DE ESTUDOS E PROJETOS (FINEP). Projeto Inovar: Ações e Resultados - 2017. Disponível em: http://www.finep.gov.br/numeros_finep/relatorio_inovar/relatorio_inovar.pdf Acesso em: 10 dezembro 2017.

GRESSLER, L.A. Introdução à pesquisa: projetos e relatórios. 2. Ed.São Paulo: Loyola, 2004.

GONÇALVES, J. E. L.; GOMES, C. A. A tecnologia: realização do trabalho. Revista de Administração de Empresas, São Paulo, v. 33, n. 1, p. 106-121, 1993. 
HOLANDA, F. C. S.; MOURA, T. G. Z.; MAHL, A. A. Fomento às inovações nas micro e pequenas empresas avaliação das empresas baianas sobre editais de subvenção econômica. Navus-Revista de Gestão e Tecnologia, v. 5, n. 1, p. 36-50, 2015.

KOTESKI, M. A. As micro e pequenas empresas no contexto econômico brasileiro. Revista FAE Business, v. 8, n. 1, p. 16-18, 2004.

LA ROVERE, R. L. As pequenas e médias empresas na economia do conhecimento: implicações para políticas de inovação. Informação e globalização na era do conhecimento. Rio de Janeiro: Campus, p. 145-163, 1999.

MARCONI, M.A.; LAKATOS, E. Técnicas de pesquisa. São Paulo: Atlas, 1990.

MAÇANEIRO, M. B. Fontes de financiamento à inovação: incentivos e óbices às micro e pequenas empresas: estudo de casos múltiplos no estado do Paraná. Curitiba 2008. Dissertação de Mestrado em Administração. UFPR.

MENDES, R. D. S.; KANIKADAN A. Y. S. Gestão estratégica de inovação como perspectiva para mudança em micro e pequenas empresas. Estudo de Caso na Nutrisho. $26^{\text {a }}$ Conferência Anprotec de Empreendedorismo e Ambientes de Inovação. Fortaleza / CE. 2016.

MORAES, M. B., LIMA, E. O., LOBOSCO, A. Competências para inovar em pequenas e médias empresas tecnológicas. Revista de Administração e Inovação, v. 8, n. 4, p. 206-226, 2011.

MOREIRA, S. Microcrédito, ocupação e renda. MINISTÉRIO DO TRABALHO E EMPREGO. Disponível em: http://www.abscm.com.br/download/publicacoes/Microcredito_\%200cupacao\%20e\%20renda .pdf . Acessado em: 08 de agosto de 17.

NUNES, K. P.; MIRANDA, L, C.; FERREIRA, K. A. S. Dura lição: Aprendendo com os pequenos empresários que fecharam seus negócios. Revista da Micro e Pequena Empresa, v. 4, n. 2, p. 49-63, 2011.

OLIVEIRA, W. L.; COSTA, A. C.; ROMÃO, L. M.; OLIVEIRA, H. C. Mortalidade de micro e pequenas empresas: o que fazer pela sustentabilidade do empreendimento? Revista Livre de Sustentabilidade e Empreendedorismo, v. 1, n. 3, p. 129-150, 2016.

OSIRO, F., DE LIMA, E. P., LOCH, S., DE ANDRADE JÚNIOR, P. P. A inovação na empresa: processos e estratégias. ENCONTRO NACIONAL DE ENGENHARIA DE PRODUÇÃO-ENEGEP, v. 99, p. 19, 1999.

PEREIRA, F. M., GRAPEGGIA, M., EMMENDOERFER, M. L., TRÊS, L.D. Fatores de inovação para a sobrevivência das micro e pequenas empresas no Brasil. RAI - Revista de 
Administração e Inovação, v. 6, n. 1, 2009.

RIBEIRO, E. H.; MORAES J. R.; RUIZ, A. U. Identificação e caracterização de dificuldades na execução de projetos de P\&D financiados pela FINEP. VI Congresso Nacional de Excelência em Gestão - Niterói / RJ, 2010.

SILVA, F. M.; OLIVEIRA, E. A. D. A. Q.; MORAES, M. B.; MONTEIRO, R. D. C. R. V. Apoio à inovação em pequenas empresas: uma análise dos programas da FINEP nos anos de 2012 a 2014. XVI Congresso Latino Iberoamericano de Gestão Tecnológica - Porto Alegre / RS, 2015.

SILVA, F. M.; MORAES, M. B.; OLIVEIRA, E. A. A. Q. O processo de desenvolvimento da inovação nas pequenas e médias empresas de base tecnológica. Revista Brasileira de Gestão e Desenvolvimento Regional, v. 12, n. 5, 2016.

SCHUMPETER, J. A. Teoria do desenvolvimento econômico. São Paulo: Abril Cultural, 1982. (Série Os economistas).

TERENCE, A. C. F. Planejamento estratégico como ferramenta de competitividade na pequena empresa. 2002. Tese de Doutorado. Universidade de São Paulo. 